\title{
Evaluation of Melissa Officinalis Extract and Oil as Eco-friendly Corrosion Inhibitor for Carbon Steel in Acidic Chloride Solutions
}

\section{AYSSAR NAHLÉ ${ }^{*}$, YASSIR EL OUADI ${ }^{2}$, ABDELHAMID BOUYANZER ${ }^{2}$, LHOU MAJIDI ${ }^{3}$, JULIEN PAOLINI' ${ }^{4}$, JEAN MARIE DESJOBERT ${ }^{4}$, JEAN COSTA ${ }^{4}$, NABILA CHAHBOUN ${ }^{5,6}$, ABDELKADER ZARROUK ${ }^{2}$ and BELKHEIR HAMMOUTI ${ }^{2}$}

${ }^{1}$ Department of Chemistry, College of Sciences, University of Sharjah, Sharjah, P.O.Box: 27272, United Arab Emirates.

${ }^{2}$ Laboratoire de Chimie Appliquée et Environnement (LCAE-URAC18),

Faculté des Sciences, B.P. 717, 60000 Oujda, Morocco.

${ }^{3}$ Laboratoire des Substances Naturelles \&Synthese et Dynamique Moléculaire,

Faculté des Sciences et Techniques, Errachidia, Morocco.

${ }^{4}$ Université de Corse, UMR CNRS 6134, Laboratoire de Chimie des Produits Naturels,

Faculté des Sciences et Techniques, Corse, France.

${ }^{5}$ Laboratoire de Biotechnologie, Environnement et Qualité (LABEQ), Département de Biologie,

Faculté des Sciences, Université Ibn Tofaïl, BP 133, 14000 Kenitra, Morocco.

${ }^{6}$ Laboratoire de Procédés de Séparation, Département de Chimie, Faculté des Sciences,

Université Ibn Tofail 133, 14000 Kenitra, Morocco.

${ }^{*}$ Corresponding author E-mail: anahle@sharjah.ac.ae

http://dx.doi.org/10.13005/ojc/320417

(Received: July 01, 2016; Accepted: August 05, 2016)

\begin{abstract}
The extract (E) and oil of Melissa Officinalis leaves (EO) have been evaluated as a corrosion inhibitors for carbon steel in $1.0 \mathrm{M} \mathrm{HCl}$ solution by means of weight loss measurements, potentiodynamic polarization, and electrochemical impedance spectroscopy (EIS). Tafel polarization study revealed that extract (E) and oil of Melissa Officinalis (EO) act as a mixed type inhibitors. The Nyquist plots showed that with increasing the inhibitors concentrations, the charge-transfer resistance increased and the double-layer capacitance decreased, involving increased inhibition efficiency. The inhibition was found to increase with increasing the concentration of the extract (E) and oil of Melissa Officinalis (EO). The values of inhibition efficiency calculated from weight loss, Tafel polarization curves, and EIS were in good agreement. The effect of temperature on the corrosion behaviour of mild steel in $1.0 \mathrm{M} \mathrm{HCl}$ with addition of both extract (E) and oil of Melissa Officinalis (EO) was also studied and thermodynamic parameters were determined and discussed.
\end{abstract}

Keywords: Corrosion inhibition, Carbon steel, Melissa Officinalis,

Extract, Oil, Electrochemical techniques. 


\section{INTRODUCTION}

The use of chemical inhibitors is one of the most practiced methods for protecting against corrosion, especially in acid media, to prevent metal dissolution and acid consumption ${ }^{1}$. Various organic and non-organic compounds have been studied as inhibitors to protect metals from corrosion. Usually, organic compounds exert a significant influence on metal surface adsorption and therefore can be used as effective corrosion inhibitors. The efficiency of these organic corrosion inhibitors is related to the presence of polar functions containing $\mathrm{S}, \mathrm{O}$, or $\mathrm{N}$ atoms which are centres for the establishment of the adsorption process ${ }^{2-11}$.

Nevertheless, most of these synthetic organic compounds are not only expensive but also toxic for live beings. Now, the restrictive environmental regulations have made researchers to focus on the need to develop cheap, non-toxic, and environmentally benign natural corrosion inhibitors. These natural organic compounds could be either synthesized or extracted from aromatic herbs, spices, and medicinal plants. Plant extracts are viewed as an incredibly rich source of natural chemical compounds which can be extracted by simple and low-cost procedures and which are biodegradable in nature. The use as corrosion inhibitors of natural compounds extracted from leaves or seeds, for example, have been widely reported by several authors ${ }^{12-19}$.

Recently, Fouda et a ${ }^{R 0}$ used the extract of Melissa as corrosion inhibitor of carbon steel in $\mathrm{HCl}$ solutions. The encouraging results incited to examine separately extract and oil of Melissa plant on the corrosion of carbon steel in molar $\mathrm{HCl}$ using different techniques including weight loss, potentiodynamic polarization measurements, and electrochemical impedance spectroscopy (EIS). The thermodynamic of activation parameters were also calculated and discussed.

\section{EXPERIMENTAL}

\section{Inhibitors}

\section{Plant Material}

The aerial part of Melissa Officinalis was harvested in January 2013 in the wild in the mountain Assoul located Taza at the Nord-east of Morocco. A voucher specimen was deposited in the Herbarium of Faculty of Sciences, Oujda, Morocco. The dried plant material was stored in the laboratory at room temperature $(298 \mathrm{~K})$ and in the shade before the extraction.

\section{Hydrodistillation Apparatus and Procedure}

Hydrodistillation is an extraction method whose function is to extract the volatile compounds of natural products with water vapour, and is often performed using Clevenger-type apparatus, with $400 \mathrm{~mL}$ for 3 hours. The essential oil yields were measured and subsequently dried over anhydrous sodium sulfate and stored at $277 \mathrm{~K}$ in the dark before gas chromatographic determination of its composition ${ }^{18}$.

\section{Characterization and Chemical Composition of Essential Oils}

Techniques in chromatography (GC/ MS, GC-FTIR, HPLC-DAD) were available for the molecular analysis of organic compounds. The chemical components of Melissa Officinalis essential oil were determined by spectral analysis of gas chromatography and gas chromatography coupled to mass spectrometry (GC-MS), which identified six major components. GC analyses were performed using a Perkin-Elmer Autosystem GC apparatus (Waltham, MA, USA) equipped with a single injector and two flame ionization detectors (FID). The apparatus was used for simultaneous sampling with two fused-silica capillary columns $(60 \mathrm{~m}$ long with i.d. $0.22 \mathrm{~mm}$, film thickness $0.25 \mu \mathrm{m}$ ) with different stationary phases: Rtx-1 (polydimethylsiloxane) and Rtx-Wax (polyethylene glycol). The temperature program was for $333-503 \mathrm{~K}$ at $275 \mathrm{~K} / \mathrm{min}$ and then held at isothermal $503 \mathrm{~K}$ (30 min.). The carrier gas was helium (1 $\mathrm{mL} / \mathrm{min})$. Injector and detector temperatures were held at $553 \mathrm{~K}$. Split injection was conducted with a ratio split of $1: 80$. Electron ionization mass spectra were acquired with a mass range of 35-350 Da. The injected volume of oil was $0.1 \mu \mathrm{L}$. For gas chromatography-mass spectrometry, the oils obtained were investigated using a Perkin-Elmer Turbo Mass Quadrupole Detector, directly coupled to a Perkin-Elmer Auto system XL equipped with two fused-silica capillary columns $(60 \mathrm{~m}$ long with i.d. $0.22 \mathrm{~mm}$, film thickness $0.25 \mu \mathrm{m}$ ), with Rtx-1 (polydimethylsiloxane) and Rtx-Wax (polyethylene glycol). Other GC conditions were the same as 
described above. Ion source temperature was 423 $\mathrm{K}$ and energy ionization $70 \mathrm{eV}$. Electron ionization mass spectra were acquired with a mass range of 35-350 Da.

The injected volume of oil was $0.1 \mu \mathrm{L}$. Identification of the components was based (1) on the comparison of their $\mathrm{GC}$ retention indices (RI) on non-polar and polar columns, determined relative to the retention time of a series of $n$-alkanes with linear interpolation, with those of authentic compounds or literature data ${ }^{21}$, and (2) on computer matching with commercial mass spectral libraries ${ }^{21,22}$ and comparison of spectra with those in our personal library. Relative amounts of individual components were calculated on the basis of their GC peak areas on the two capillary Rtx-1 and Rtx-Wax columns, without FID response factor correction.

\section{Materials}

The steel used in this study is a carbon steel with a chemical composition 0.09 wt. \% P; 0.38 wt. $\%$ Si; 0.01 wt. \% Al; 0.05 wt. \% Mn; 0.21 wt. \% C; 0.05 wt. $\% \mathrm{~S}$ and the remainder iron $(\mathrm{Fe})$.

\section{Preparation of Solutions}

The aggressive solutions of $1.0 \mathrm{M} \mathrm{HCl}$ were prepared by dilution of analytical grade $37 \%$ $\mathrm{HCl}$ with distilled water. Inhibitors were dissolved in acid solution at the required concentrations (in $\mathrm{mL} / \mathrm{L}$ ) (volume of inhibitor/volume of blank), and the solution in the absence of inhibitor was taken as blank for comparison purposes. The test solutions were freshly prepared before each experiment by adding essential oil and extract of Melissa Officinalis directly to the corrosive solution. The concentrations of essential oils were $0.5,1$, and $2 \mathrm{~mL} / \mathrm{L}$; and those of the extract were 2,4 , and $8 \mathrm{~mL} / \mathrm{L}$.

\section{Gravimetric Study}

Gravimetric experiments were performed according to the standard methods ${ }^{23}$, the carbon steel specimens $(1.0 \mathrm{~cm} \times 1.0 \mathrm{~cm} \times 0.1 \mathrm{~cm})$ were abraded with a series of emery papers $\mathrm{SiC}$ (120, 600, and 1200 grades) and then washed with distilled water and acetone. After weighing accurately, the specimens were immersed in a $100 \mathrm{~mL}$ beaker containing $250 \mathrm{~mL}$ of $1.0 \mathrm{M} \mathrm{HCl}$ solution with and without addition of different concentrations of inhibitors. All the aggressive acid solutions were open to air. After 6 hours of acid immersion, the specimens were taken out, washed, dried, and weighed accurately. In order to get good reproducibility, all measurements were performed few times and average values were reported.

\section{Electrochemical Measurements}

The electrochemical measurements were carried out using Volta lab (Tacussel - Radiometer PGZ 100) potentiostat controlled by Tacussel corrosion analysis software model (Voltamaster 4 ) at static condition. The corrosion cell used had three electrodes. The reference electrode was a saturated calomel electrode (SCE). A platinum electrode was used as auxiliary electrode of surface area of $1 \mathrm{~cm}^{2}$. The working electrode was carbon steel of the surface $0.32 \mathrm{~cm}^{2}$. All potentials given in this study were referred to this reference electrode. The working electrode was immersed in the test solution for 30 minutes to establish a steady state open circuit potential $\left(E_{\text {ocp }}\right)$. After measuring the $E_{\text {ocp }}$, the electrochemical measurements were performed. All electrochemical tests have been performed in aerated solutions at $308 \mathrm{~K}$. The EIS experiments were conducted in the frequency range with high limit of $100 \mathrm{kHz}$ and different low limit $0.1 \mathrm{~Hz}$ at open circuit potential, with 10 points per decade, at the rest potential, after 30 min of acid immersion, by applying $10 \mathrm{mV}$ ac voltage peak-to-peak. Nyquist plots were made from these experiments. The best semicircle can be fit through the data points in the Nyquist plot using a non-linear least square fit so as to give the intersections with the $x$-axis.

The inhibition efficiency of the inhibitor was calculated from the charge transfer resistance values using the following equation:

$$
\eta_{z} \%=\frac{R_{c t}^{i}-R_{c t}^{\circ}}{R_{c t}^{i}} \times 100
$$

Where, $\mathrm{R}_{\mathrm{ct}}^{\mathrm{i}}$ and $\mathrm{R}_{\mathrm{ct}}^{\mathrm{i}}$ are the charge transfer resistance in absence and in presence of inhibitor, respectively.

After the ac impedance test, potentiodynamic polarization measurements of carbon steel substrate in inhibited and uninhibited solution were scanned from cathodic to the anodic direction, with a scan 
rate of $1 \mathrm{mV} . \mathrm{s}^{\prime \prime}$. The potentiodynamic data were analysed using the polarization VoltaMaster 4 software. The linear Tafel segments of anodic and cathodic curves were extrapolated to corrosion potential to obtain corrosion current densities $\left(I_{\text {corr }}\right)$. From the polarization curves obtained, the corrosion current $\left(\mathrm{I}_{\text {corr }}\right)$ was calculated by curve fitting using the equation:

$$
I=I_{\text {corr }}\left[\exp \left(\frac{2.3 \Delta E}{\beta_{a}}\right)-\exp \left(\frac{2.3 \Delta E}{\beta_{c}}\right)\right]
$$

The inhibition efficiency was evaluated from the measured $\mathrm{I}_{\text {corr }}$ values using the following relationship:

$\mathrm{h}_{\text {Tafel }}(\%)=\frac{I_{\text {corr }}-I_{\text {corr(i) }}}{I_{\text {corr }}} \times 100$

where $I_{\text {corr }}$ and $I_{\text {corr(i) }}$ are the corrosion current densities for steel electrode in the uninhibited and inhibited solutions, respectively.

\section{RESULTS AND DISCUSSION}

\section{Essential oil composition}

Qualitative and quantitative analyses of essential oils were carried out using GC/MS analyses. The compositions of essential oils of Melissa Officinalis are shown in Table 1.

The most important constituents of essential oils of Melissa officinalis are shown in Table 2.

\section{Gravimetric Measurements Effect of Inhibitor Concentration}

The effect of addition of oil and extract of Melissa Officinalis tested at different concentrations on the corrosion of carbon steel in $1.0 \mathrm{M} \mathrm{HCl}$ solution was also studied by weight loss method at $308 \mathrm{~K}$ after $6 \mathrm{~h}$ of immersion period. The corrosion rate $(\mathrm{v})$ and the inhibition efficiency $\left(\eta_{\mathrm{wL}} \%\right)$ were calculated by the following equations ${ }^{24}$ :

$v=\frac{W}{S t}$

$$
\eta_{\mathrm{WL}}(\%)=\frac{v_{0}-v}{v_{0}} \times 100
$$

where $\mathrm{W}$ is the three-experiment average weight loss of the carbon steel, $\mathrm{S}$ is the total surface area of the specimen, $t$ is the immersion time and $\mathrm{v}_{0}$ and $\mathrm{v}$ are values of the corrosion rate without and with addition of the inhibitor, respectively.

Table 3 gives the results of the weight loss measurements for the corrosion of carbon steel in $1.0 \mathrm{M} \mathrm{HCl}$ solution in the absence and presence of oil and extract of Melissa Officinalis at $308 \mathrm{~K}$. Analysis of Table 3 reveals that as the concentration of inhibitors increases, the inhibition efficiency $\left(\eta_{W L} \%\right)$ increases. This is because more surface area of carbon steel is covered by increasing inhibitors concentration.

\section{Effect of Temperature}

In order to study the temperature dependence of corrosion rates in uninhibited and inhibited solutions, gravimetric measurements were carried out at the temperatures ranging from $313 \mathrm{~K}$ to $343 \mathrm{~K}$ in the absence and presence of optimum concentration of inhibitors $(2.0 \mathrm{~mL} / \mathrm{L}$ for $\mathrm{EO}$, and 8.0 $\mathrm{mL} / \mathrm{L}$ for $\mathrm{E})$. The calculated values of the corrosion rates and inhibition efficiencies within the studied temperature range are shown in Table 4.

Generally, the corrosion rates of carbon steel in acidic solutions increased with the rise in temperature. This is due to a decrease in the overpotential of the hydrogen evolution reaction, resulting in higher dissolution rates of metals. The higher rate of hydrogen gas generation also increasingly agitates the metal corrodent/interface and depending on the nature of the metal-inhibitor interactions, this could also hinder the inhibitor adsorption or perturb already adsorbed inhibitor. On the other hand, for inhibitor species that react with the metal surface, increasing the temperature of the system could augment the interaction between the metal surface and the inhibitor leading to higher surface coverage.

Table 4 showed that the corrosion rate increased with increasing the temperature both in uninhibited and inhibited solutions while the 
inhibition efficiency of the essential oil decreased with temperature. On the other hand, the inhibition efficiency of the extract remained almost constant. A decrease in inhibition efficiency with the increase temperature in presence of essential oil might be due to the weakening of physical adsorption, while in case of the extract, the constant value of the inhibition efficiency could be due to chemistry.

Arrhenius and transition state plots were used for determination of $\mathrm{E}_{\mathrm{a}}$ (activation energy), $\Delta \mathrm{H}_{\mathrm{a}}$ (activation enthalpy) and $\Delta \mathrm{S}_{\mathrm{a}}$ (activation entropy) at the studied temperature $313,323,333$, and $343 \mathrm{~K}$ for the carbon steel in the presence and absence of inhibitors (Equation 6):

$$
\mathrm{V}=A e^{-E_{a} / R T}
$$

where $\mathrm{v}$ is the corrosion rate, $\mathrm{A}$ is the pre-exponential factor, $E_{a}\left(\mathrm{~J} \mathrm{~mol}^{-1}\right)$ is the activation energy, and $R$ is the gas constant (8.314 J.mol-1.K-1).

To solve this equation, we take natural logs of both sides (common logs could be used as well):

$\ln v=\left(\frac{-E_{a}}{R T}\right)+\ln A$

The values of $E_{a}$ were calculated (Table 5) from the slope (slope $=-E_{a} / R$ ) of the straight line of the $x$-axis (In v) and $y$-axis (1000/T) of the graph by using of Arrhenius plot for the carbon steel in $1.0 \mathrm{M}$ $\mathrm{HCl}$ in the with and without inhibitors (Figure 1).

The transition state equation was used to calculate the $\Delta \mathrm{H}_{\mathrm{a}}$ and $\Delta \mathrm{S}_{\mathrm{a}}$ :

$v=\frac{R T}{N h} \exp \left(\frac{\Delta S_{a}}{R}\right) \exp \left(\frac{-\Delta H_{a}}{R T}\right)$

where $R$ is the universal gas constant, $A$ is the Arrhenius pre-exponential factor, $h$ is Plank's constant, $\mathrm{N}$ is Avogrado's number, $\mathrm{E}_{\mathrm{a}}$ is the activation energy, $\mathrm{T}$ is the absolute temperature in Kelvin, $\Delta \mathrm{S}_{\mathrm{a}}$ is the entropy of activation, and $\Delta \mathrm{H}_{\mathrm{a}}$ is the enthalpy of activation. To carry out simple calculations, Equation (6) was rearranged to become:

$\ln \left(\frac{\mathrm{v}}{T}\right)=\left(-\frac{\Delta H_{a}}{R T}\right)+\left[\ln \left(\frac{R}{N h}\right)+\left(\frac{\Delta S_{a}}{R}\right)\right]$

A plot of In $(\mathrm{v} / \mathrm{T})$ against $1000 / \mathrm{T}$ gives a straight line with the slope equal to $(\Delta \mathrm{Ha} / \mathrm{R})$ and intercept equal to $\left[\ln (\mathrm{R} / \mathrm{Nh})+\left(\Delta \mathrm{S}_{\mathrm{a}} / \mathrm{R}\right)\right]$, as shown in Figure 2. The $\Delta \mathrm{H}_{\mathrm{a}}$ and $\Delta \mathrm{S}_{\mathrm{a}}$ values were calculated and are displayed in Table 5.

From Table 5, the activation energy increases in the presence of the EO, implying that a physical adsorption (electrostatic) process occurred in the initial stage. This phenomenon may be attributed to the change in the mechanism of the corrosion process in the presence of adsorbed inhibitor molecules. It is often interpreted by physical adsorption leading to the formation of an adsorptive film of electrostatic character ${ }^{25-28}$. This conclusion is corroborated by the decrease in inhibition efficiency with increasing temperature (Table 5). According to Szauer and Brand ${ }^{29}$, the increase in activation energy can be attributed to the decrease in the adsorption of the inhibitor on the carbon steel surface with increases in temperature ${ }^{29}$. However, the lower value of $E_{a}$ in inhibited solution compared to uninhibited solution can be explained by strong chemisorption bond between the inhibitor and the metal. Some authors reported that electrostatic adsorption proceeds irrespective of the fact that the $\mathrm{E}_{a}$ value in the presence of inhibitor is lower than that in free solution $^{30}$. In addition, the $\mathrm{E}_{\mathrm{a}}$ values are greater than $20 \mathrm{~kJ} \mathrm{~mol}^{-1}$ in both the presence and absence of the inhibitor, which indicate that the entire process is controlled by the surface reaction ${ }^{31}$. The positive sign of the enthalpies $\Delta \mathrm{H}_{\mathrm{a}}$ reûects the endothermic nature of the steel dissolution process whereas large negative values of entropies $\Delta S_{a}$ imply that the activated complex in the rate determining step represents an association rather than a dissociation step, meaning that a decrease in disordering takes place on going from reactants to the activated complex ${ }^{32,33}$. 


\section{Electrochemical Experiments Potentiodynamic Polarization Curves}

Figures $3(\mathrm{~A})$ and $4(\mathrm{~B})$ represent the potentiodynamic polarisation curves of carbon steel in a $1.0 \mathrm{M} \mathrm{HCl}$ solution in the absence and presence of oil and extract of Melissa Officinalis at $308 \mathrm{~K}$.

The respective electrochemical parameters (i.e., corrosion potential $\left(\mathrm{E}_{\text {corr }}\right)$, corrosion current density $\left(I_{\text {corr }}\right)$, and the anodic $\left(\beta_{\mathrm{a}}\right)$ and cathodic $\left(\beta_{\mathrm{c}}\right)$ Tafel constants, as shown in Table 6, were derived from Tafel plots.

From the potentiodynamic polarisation curves, it can be seen that the extracts caused a decrease in both anodic and cathodic current densities, which is most likely due to the adsorption of the organic compounds present in the oil and extract of Melissa Officinalis at the active sites of the electrode surface. This also slowed both metallic dissolution and hydrogen evolution and consequently slowed down the corrosion process. The two extracts exhibited the same behaviour.

From Table 6, it is also clear that there is a shift toward cathodic region in the values of corrosion potential $\left(E_{\text {corr }}\right)$. In the literature ${ }^{34,35}$, it has been reported that if the displacement in $E_{\text {corr(inh) }}$ is more than $85 \mathrm{mV}$ vs. SCE from $\mathrm{E}_{\text {corr }}$, the inhibitor can be seen as a cathodic or anodic type; and if displacement in $\mathrm{E}_{\text {corr(inh) }}$ is less than $85 \mathrm{mV}$ vs. SCE, the inhibitor can be seen as mixed type. In our study the maximum displacement in $\mathrm{E}_{\text {corr }}$ value was $40 \mathrm{mV}$ vs. SCE toward cathodic region, which indicates that these investigated oil and extract of Melissa Officinalis are mixed type inhibitors. $\mathrm{CaO}^{36}$ pointed out that the inhibitory action on the metal surface takes place with geometrical blockage of the active site. It can be observed from Table 6 that the $I_{\text {cor }}$ values decrease considerably in the presence of $E O$ and $E$ and decrease with increasing the inhibitor concentration. Correspondingly, $\eta_{\text {Tafel }}(\%)$ values increase with increasing the inhibitor concentration reaching a maximum value at $2 \mathrm{~mL} / \mathrm{L}$ for $\mathrm{EO}$ and $8 \mathrm{~mL} / \mathrm{L}$ for $\mathrm{E}$. The cathodic Tafel slope $\left(\beta_{\mathrm{c}}\right)$ and the anodic Tafel slope $\left(\beta_{\mathrm{a}}\right)$ of oil and extract of Melissa Officinalis changed with inhibitors concentration. This observation suggests that the inhibitors molecules controlled the two reactions and adsorbed on the metal surface by blocking the active sites on the metal surface, retarding the corrosion reaction.

\section{Electrochemical Impedance Measurements (EIS)}

The electrochemical impedance diagrams for carbon steel in $1.0 \mathrm{M} \mathrm{HCl}$ solution in the absence and presence of various concentrations of oil and extract of Melissa Officinalis are shown in Figures 4(A) and 4(B). Table 7 summarizes impedance data from the EIS experiments carried out both in the absence and presence of oil and extract of Melissa Officinalis at various concentrations. The electrochemical impedance diagrams show only one depressed capacitive loop, which is attributed to the one time constant, in the absence and presence of oil and extract of Melissa Officinalis, which indicates two significant effects: the chargetransfer resistance significantly increases, and the $f_{\max }$ decreases, in the presence of both inhibitors, decreasing the capacitance value, which may be caused by reduction in the local dielectric constant and/or by an increase in the thickness of the electrical double-layer.

These results show that the presence of the inhibitors modifies the electric double-layer structure suggesting that the inhibitor molecules act by adsorption at the metal/solution interface. The solution resistance (Rs) is identical in the absence and presence of oil and extract of Melissa Officinalis and equal to $1.2 \Omega . \mathrm{cm}^{2}$. Deviations from a perfect circular shape indicate frequency dispersion of interfacial impedance. This anomalous phenomenon is attributed in the literature to the non-homogeneity of the electrode surface arising from the surface roughness or interfacial phenomena ${ }^{37-40}$. The chargetransfer resistance $\left(R_{c t}\right)$ values were calculated from the difference in impedances at lower and higher frequencies. The double-layer capacitance $\left(\mathrm{C}_{\mathrm{dl}}\right)$ was calculated from the following equation:

$$
C_{d l}=\frac{1}{2 \pi f_{\max } R_{c t}}
$$

where $f_{\max }$ is the frequency at which the imaginary component of the impedance is maximal. $A_{\mathrm{dl}}$ value of $54.58 \mu \mathrm{F} . \mathrm{cm}^{-2}$ was determined for the carbon steel electrode in $1.0 \mathrm{M} \mathrm{HCl}$. 
Data presented in Table 7 show that the value of $R_{c t}$ increases in presence of oil and extract of Melissa Officinalis. The value of $C_{d l}$ is always smaller in the presence of the inhibitors than in its absence, as a result of the effective adsorption of the inhibitors. It is apparent that a causal relationship exists between adsorption and inhibition. Besides, it is clear from the Table 7 that by increasing the inhibitors concentrations, the $\mathrm{C}_{\mathrm{dl}}$ values tend to decrease and the inhibition efficiency increases. This behaviour was the result of an increase in the surface coverage by the inhibitors molecules of oil and extract of Melissa Officinalis, which led to an increase in the inhibition efficiency. The decrease in $\mathrm{C}_{\mathrm{dl}}$ values may be considered in terms of Helmholtz model ${ }^{41}$ :

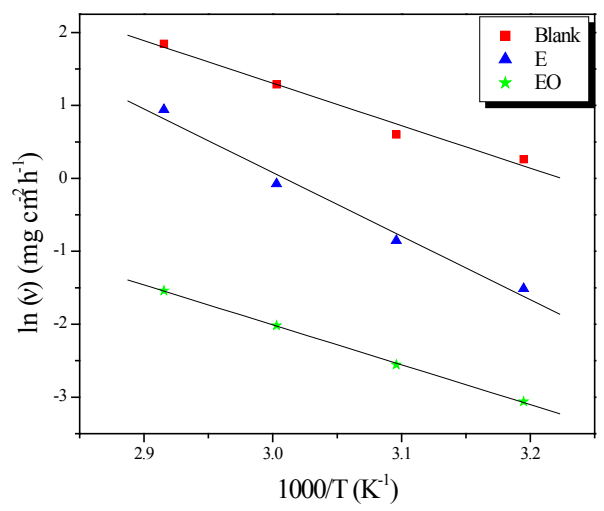

Fig. 1: Arrhenius plots for the corrosion rate of carbon steel in $1.0 \mathrm{M} \mathrm{HCl}$ solution in absence and presence of inhibitors

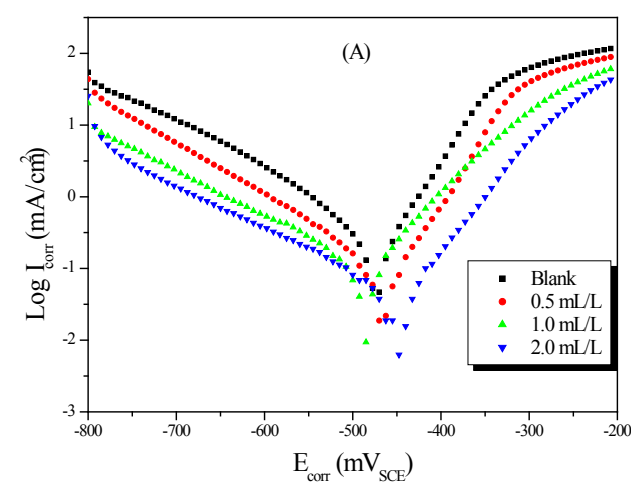

$C_{d l}=\frac{\varepsilon_{o} \varepsilon}{\delta} S$

where $\mathcal{E}$ is the dielectric constant of the medium, $\varepsilon_{0}$ is the vacuum permittivity, $S$ is the electrode area, and $\delta$ is the thickness of the protective layer. In fact, the decrease in $\mathrm{C}_{\mathrm{dl}}$ values can result from a decrease in local dielectric constant and/or an increase in the thickness of the electrical double-layer ${ }^{42}$.

The corrosion rate of carbon steel in $1.0 \mathrm{M}$ $\mathrm{HCl}$ solution is controlled by both hydrogen evolution reaction and dissolution reaction of this metal. It is generally accepted that the corrosion inhibition

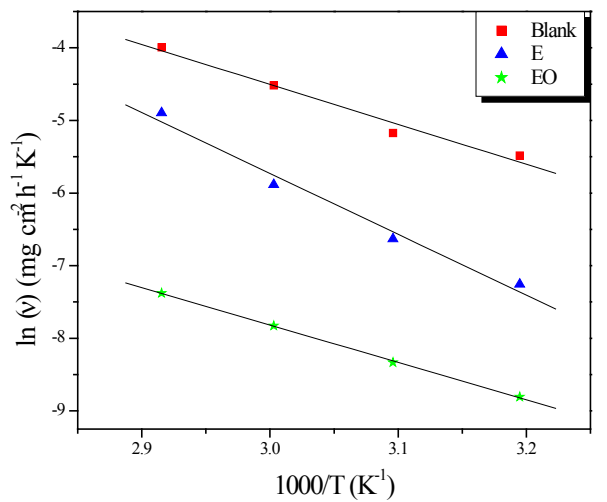

Fig. 2: $\mathrm{Ln}(\mathrm{v} / \mathrm{T})$ versus $1 / \mathrm{T}$ for the corrosion of carbon steel in $1.0 \mathrm{M} \mathrm{HCl}$ in absence and presence of inhibitors

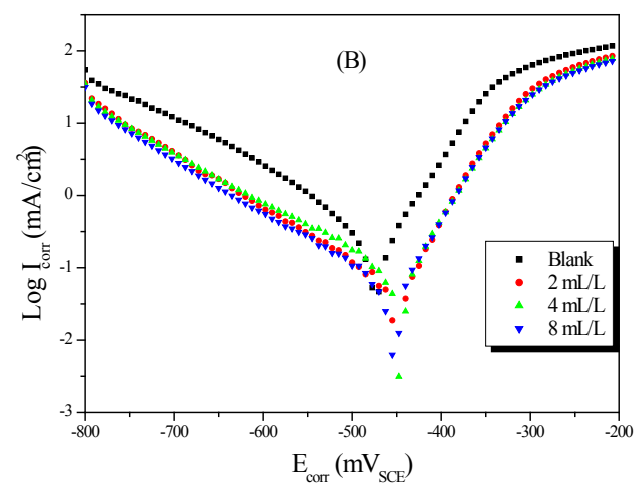

Fig. 3: Polarisation curves for carbon steel in $1.0 \mathrm{M} \mathrm{HCl}$ in the absence and presence of oil and extract of Melissa Officinalis concentrations: Extract oil (A) and extract of Melissa Officinalis (B) 
Table 1: Chemical constituents of Melissa officinalis essential oil (EO) (\%)

\begin{tabular}{|c|c|c|c|c|}
\hline Compounds & Ir I & Ir a & Ir $p$ & $\%$ \\
\hline$\alpha$-pinene & 936 & 929 & 1019 & 0.3 \\
\hline oct-1-en-3-ol & 962 & 961 & 1440 & 0.5 \\
\hline Sabinene & 973 & 964 & 1117 & 0.4 \\
\hline$\beta$-pinene & 978 & 969 & 1107 & 0.5 \\
\hline Myrcene & 987 & 980 & 1155 & 1.1 \\
\hline$\alpha$-terpinene & 1013 & 1008 & 1175 & 0.3 \\
\hline p-Cymene & 1015 & 1011 & 1263 & 0.2 \\
\hline Cineole 1,8 & 1024 & 1020 & 1207 & 0.9 \\
\hline Limonene & 1025 & 1020 & 1196 & 0.6 \\
\hline (Z) $\beta$-Ocimene & 1029 & 1025 & 1220 & 0.8 \\
\hline (E) $\beta$-Ocimene & 1041 & 1035 & 1234 & 0.1 \\
\hline$\gamma$-terpinene & 1051 & 1048 & 1240 & 0.7 \\
\hline E-hydrate de sabinene & 1053 & 1056 & 1457 & 4.6 \\
\hline P-Mentha-3,8-diene & 1059 & 1059 & 1259 & 0.4 \\
\hline terpinolene & 1082 & 1078 & 1277 & 0.2 \\
\hline Z-hydrate de sabinene & 1082 & 1083 & 1536 & 0.5 \\
\hline 1-octen-3-ol acetate & 1093 & 1094 & 1371 & 1.8 \\
\hline 3-octenyl acetate & 1110 & 1107 & 1328 & 0.2 \\
\hline P-Menth-3-en-8-ol & & 1136 & 1602 & 8.8 \\
\hline Menthone & 1136 & 1136 & 1483 & 1.0 \\
\hline isomenthone & 1146 & 1140 & 1457 & 2.7 \\
\hline Neomenthol & 1156 & 1154 & 1637 & 2.4 \\
\hline Terpinen-4-ol & 1164 & 1166 & 1598 & 3.5 \\
\hline$\beta$-Terpineol & 1176 & 1175 & 1665 & 0.5 \\
\hline Pulegone & 1215 & 1221 & 1639 & 8.8 \\
\hline Z-piperitone oxyde & 1230 & 1235 & 1717 & 7.3 \\
\hline Pseudodisphenol & 1245 & 1248 & & 0.2 \\
\hline Isopulegylacetate 1 & 1263 & 1258 & 1631 & 0.2 \\
\hline Neomenthylacetate & 1263 & 1263 & 1524 & 1.9 \\
\hline Thymol & 1266 & 1263 & 2159 & 0.3 \\
\hline Bornylacetate & 1270 & 1270 & 1572 & 0.3 \\
\hline Diosphenol & 1276 & 1279 & 1790 & 1.0 \\
\hline Menthylacetate & 1280 & 1279 & 1557 & 1.0 \\
\hline Piperitenone & 1318 & 1313 & 1900 & 1.6 \\
\hline Piperitenone oxyde & 1335 & 1341 & 1939 & 8.4 \\
\hline E-jasmone & 1364 & 1369 & 1890 & 0.2 \\
\hline$\alpha$-Copaene & 1379 & 1375 & 1483 & 0.1 \\
\hline Nepetalactone & 1360 & 1379 & 1978 & 1.2 \\
\hline P-Mentha-1,2,3-triol & & 1395 & 1880 & 13.1 \\
\hline$\alpha$-Gurjunene & 1413 & 1409 & 1528 & 0.1 \\
\hline E-Caryophyllene & 1421 & 1420 & 1591 & 2.8 \\
\hline Cadina-3,5-diene & 1448 & 1441 & & 0.3 \\
\hline Trans- $\beta$-farnesene & 1446 & 1448 & 1661 & 0.2 \\
\hline$\alpha$-Humulene & 1455 & 1450 & 1665 & 0.3 \\
\hline Cis Muurola-4(14),5-diene & 1462 & 1458 & & 0.7 \\
\hline Germacrene D & 1479 & 1478 & 1706 & 3.4 \\
\hline Bicyclogermacrene & 1494 & 1491 & 1725 & 0.4 \\
\hline$\gamma$-Cadinene & 1507 & 1505 & 1756 & 0.1 \\
\hline Calamenene & 1517 & 1509 & 1817 & 0.3 \\
\hline$\delta$-Cadinene & 1520 & 1514 & 1752 & 0.1 \\
\hline Spathulenol & 1572 & 1564 & 2101 & 0.4 \\
\hline Caryophyllene oxyde & 1578 & 1569 & 1965 & 0.5 \\
\hline Viridiflorol & 1592 & 1581 & 2064 & 0.3 \\
\hline 1,10-di-epi-Cubenol & 1615 & 1603 & 2040 & 0.4 \\
\hline$\alpha$-cadinol & 1643 & 1638 & 2209 & 0.4 \\
\hline Total & 88.7 & & & \\
\hline
\end{tabular}


occurs due to the adsorption of organic molecules at the metal/solution interface and the adsorption itself depends on the molecule's chemical composition, the temperature, and the electrochemical potential at the metal/solution interface. In fact, the solvent $\mathrm{H}_{2} \mathrm{O}$ molecules could also adsorb at metal/solution interface ${ }^{43}$. Therefore, the adsorption of organic inhibitor molecules from aqueous solution can be regarded as a substitution adsorption process between the organic compound in the aqueous phase $\left[\mathrm{Org}_{(\mathrm{sol})}\right]$ and water molecules on the metal surface $\left[\mathrm{H}_{2} \mathrm{O}_{(\text {ads })}\right]^{44}$.

$$
\mathrm{Org}_{(s o l)}+x \mathrm{H}_{2} \mathrm{O} \rightarrow \mathrm{Org}_{(a d s)}+x \mathrm{H}_{2} \mathrm{O}_{(s o l)}
$$

where $x$ is the size ratio, that is, the number of water molecules replaced by one organic inhibitor.

According to the detailed mechanism above, displacement of some adsorbed water molecules might take place on the metal surface by inhibitor

Table 2: The major components of Melissa officinalis essential oils

\begin{tabular}{lc}
\hline Major components & $\%$ \\
\hline E-hydrate de sabinene & 4.6 \\
Z-piperitoneoxyde & 7.3 \\
Piperitenoneoxyde & 8.4 \\
Pulegone & 8.8 \\
P-Menth-3-en-8-ol & 8.8 \\
P-Mentha-1,2,3-triol & 13.1 \\
\hline
\end{tabular}

Table 3: Gravimetric results of carbon steel in $1.0 \mathrm{M} \mathrm{HCl}$ at various concentrations of oil (EO) and extract (E) of Melissa Officinalis at $308 \mathrm{~K}$

\begin{tabular}{|c|c|c|c|}
\hline Medium & $\begin{array}{c}\text { Inhibitor } \\
\left(\mathrm{mL} \mathrm{L}^{-1}\right)\end{array}$ & $\begin{array}{c}v \\
\left(\mathbf{m g} \cdot \mathrm{cm}^{-2} \cdot \mathrm{h}^{-1}\right)\end{array}$ & $\begin{array}{l}\eta_{w L} \\
(\%)\end{array}$ \\
\hline \multirow[t]{2}{*}{ Blank } & $\longrightarrow$ & 0.320 & 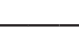 \\
\hline & 0.5 & 0.103 & 67.9 \\
\hline \multirow[t]{3}{*}{ EO } & 1.0 & 0.054 & 83.0 \\
\hline & 2.0 & 0.017 & 94.7 \\
\hline & 2.0 & 0.120 & 62.5 \\
\hline \multirow[t]{2}{*}{$E$} & 4.0 & 0.053 & 83.5 \\
\hline & 8.0 & 0.033 & 86.7 \\
\hline
\end{tabular}

species. The increase in efficiency of inhibition of oil and extract of Melissa Officinalis indicates that the inhibitors molecules are adsorbed on the carbon steel surface with higher concentration, leading to greater surface coverage $(\theta)$. It has generally been proved that the first step in the adsorption of an organic inhibitor on a metal surface usually involves the replacement of one or more of water molecules adsorbed at the metal surface by the investigated inhibitors molecules ${ }^{45}$.

Adsorption process is usually described by isotherms. The most frequently used isotherms include Langmuir, Temkin, Frumkin,... ${ }^{46}$. Langmuir isotherm was tested for its fit to the experimental data. Langmuir adsorption isotherm is given by following equation:

$\frac{C_{i n h}}{\theta}=\frac{1}{K_{a d s}}+C_{i n h}$

where $\mathrm{C}_{\text {inh }}$ is the inhibitor concentration, and $\mathrm{K}_{\mathrm{ads}}$ the adsorptive equilibrium constant, $\theta=\mathrm{E} \% / 100$ representing the degree of adsorption.

The plot of the $\left(C_{i n h} / \theta\right)$ vs $C_{i n h}$ fitted the gravimetric data follow the Langmuir adsorption isotherm (Figure 5).

Table 4: Corrosion parameters for carbon steel in $1.0 \mathrm{M} \mathrm{HCl}$ in absence and presence of optimum concentration of the inhibitors (2.0 $\mathrm{mL} / \mathrm{L}$ for EO, and $8.0 \mathrm{~mL} / \mathrm{L}$ for E) studied at different temperatures

\begin{tabular}{|c|c|c|c|c|}
\hline $\begin{array}{l}\text { Temp. } \\
\text { (K) }\end{array}$ & Medium & $\begin{array}{c}v \\
\left(\mathrm{mg} \cdot \mathrm{cm}^{-2} \cdot \mathrm{h}^{-1}\right)\end{array}$ & $\theta$ & $\begin{array}{l}\eta_{W L} \\
(\%)\end{array}$ \\
\hline \multirow[t]{3}{*}{313} & Blank & 1.300 & $\longrightarrow$ & $\longrightarrow$ \\
\hline & EO & 0.220 & 0.83 & 83.0 \\
\hline & $E$ & 0.047 & 0.96 & 96.4 \\
\hline \multirow[t]{3}{*}{323} & Blank & 1.828 & $\longrightarrow$ & $\longrightarrow$ \\
\hline & EO & 0.425 & 0.76 & 76.7 \\
\hline & $E$ & 0.078 & 0.95 & 95.7 \\
\hline \multirow[t]{3}{*}{333} & Blank & 3.635 & - & $\longrightarrow$ \\
\hline & EO & 0.926 & 0.74 & 74.5 \\
\hline & $E$ & 0.133 & 0.96 & 96.3 \\
\hline \multirow[t]{3}{*}{343} & Blank & 6.336 & $\longrightarrow$ & $\longrightarrow$ \\
\hline & EO & 2.562 & 0.59 & 59.6 \\
\hline & $E$ & 0.214 & 0.96 & 96.6 \\
\hline
\end{tabular}



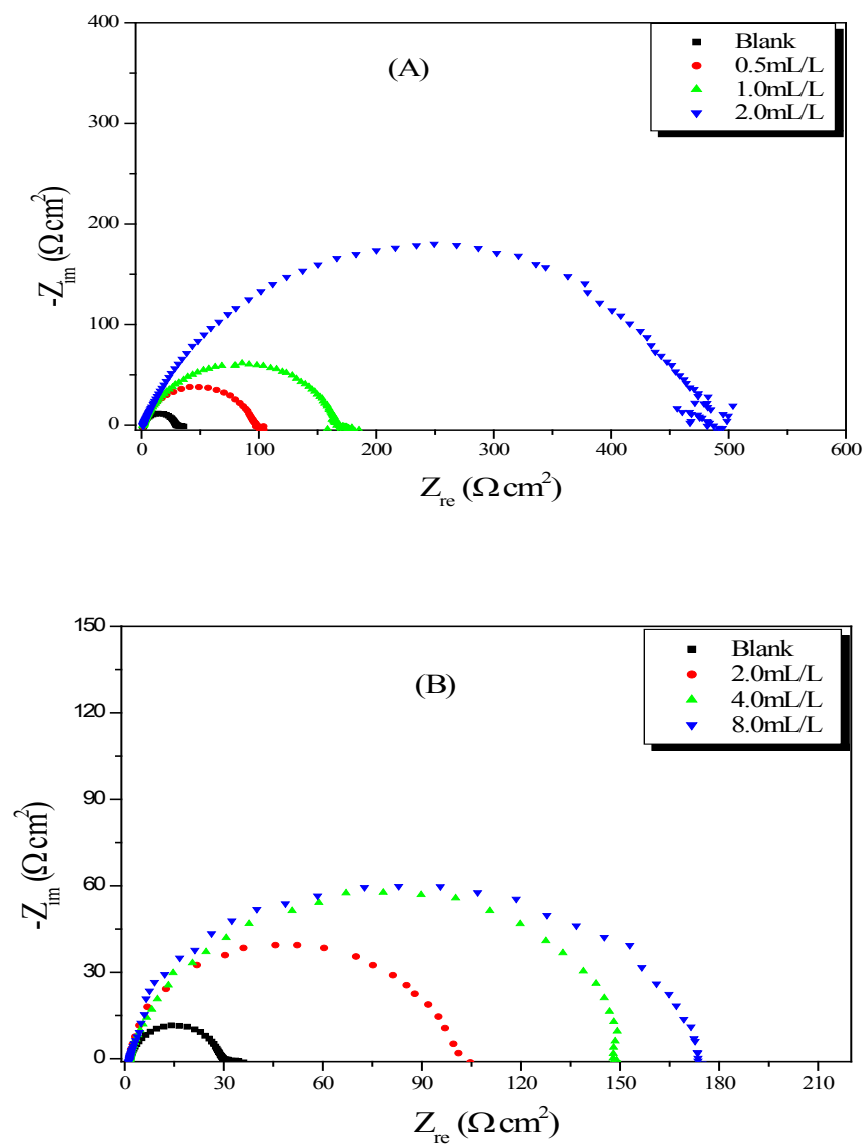

Fig. 4: Impedance diagrams obtained for carbon steel in $1.0 \mathrm{M} \mathrm{HCl}$ in the absence and presence of various oil and extract of Melissa Officinalis concentrations: Extract oil $(A)$ and extract of Melissa Officinalis (B)

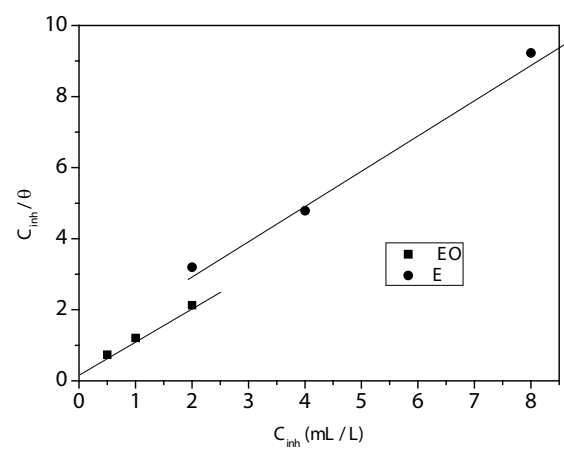

Fig. 5: Langmuir adsorption isotherm of $E O$ and $E$ on carbon steel in $1 \mathrm{M} \mathrm{HCl}$
Table 5: Activation parameters for the carbon steel dissolution in $1.0 \mathrm{M} \mathrm{HCl}$ in the absence and the presence of inhibitors at optimum concentration $(2.0 \mathrm{~mL} / \mathrm{L}$ for EO, and $8.0 \mathrm{~mL} / \mathrm{L}$ for E)

\begin{tabular}{lccc}
\hline Medium & $\begin{array}{c}\mathbf{E}_{\mathrm{a}} \\
(\mathrm{KJ} / \mathrm{mol})\end{array}$ & $\begin{array}{c}\Delta \mathbf{H}_{\mathrm{a}} \\
(\mathbf{K J} / \mathbf{m o l})\end{array}$ & $\begin{array}{c}\Delta \mathbf{S}_{\mathrm{a}} \\
(\mathbf{J} / \mathbf{m o l} . \mathbf{K})\end{array}$ \\
\hline Blank & 48.41 & 45.69 & -97.92 \\
EO & 72.39 & 69.67 & -36.42 \\
E & 45.48 & 42.76 & -134.27 \\
\hline
\end{tabular}


It has been postulated in several works that natural plants (extract or oil) contain infinite components at different contents and the inhibition of corrosion takes place by intermolecular synergistic effect of the various components of inhibitor ${ }^{47-49}$. The known composition of essential oil facilitates the possibility of action of the various molecules below as the major components having $\mathrm{OH}$ group or ketone functions known as active centres of adsorption as shown below.<smiles>CC(C)C1CCC(C)(O)C(O)C1O</smiles>

$13.1 \%$<smiles>CC1=CCC(C(C)(C)O)CC1</smiles>

$8.8 \%$<smiles>CC(C)=C1CC[C@@H](C)CC1=O</smiles>

$8.8 \%$<smiles>CC(C)=C1CCC2(C)OC2C1=O</smiles>

$8.4 \%$

Table 6: Electrochemical parameters of carbon steel at various concentrations of Melissa Officinalis oil and extract at $308 \mathrm{~K}$

\begin{tabular}{|c|c|c|c|c|c|c|}
\hline Medium & Conc. & $\begin{array}{c}-E_{\text {corr }} \\
\text { (mV vs. SCE) }\end{array}$ & $\left.\begin{array}{c}-b_{c} \\
(m V . d e c \\
-1\end{array}\right)$ & $\begin{array}{c}\mathrm{b}_{\mathrm{a}} \\
\left(\mathrm{mV} \cdot \mathrm{dec}^{-1}\right)\end{array}$ & $\begin{array}{c}I_{\text {corr }} \\
\left(\mu \mathrm{A} \cdot \mathrm{cm}^{-2}\right)\end{array}$ & Tafel $(\%)$ \\
\hline \multirow[t]{2}{*}{ Blank } & $1.0 \mathrm{M}$ & 450 & 144 & 67 & 361.8 & - \\
\hline & $0.5 \mathrm{~mL} / \mathrm{L}$ & 490 & 143 & 65 & 135.7 & 62.5 \\
\hline \multirow[t]{3}{*}{ EO } & $1.0 \mathrm{~mL} / \mathrm{L}$ & 490 & 147 & 72 & 80.3 & 77.8 \\
\hline & $2.0 \mathrm{~mL} / \mathrm{L}$ & 490 & 176 & 71 & 50.9 & 85.9 \\
\hline & $2.0 \mathrm{~mL} / \mathrm{L}$ & 470 & 195 & 61 & 119.8 & 66.9 \\
\hline \multirow[t]{2}{*}{$E$} & $4.0 \mathrm{~mL} / \mathrm{L}$ & 470 & 152 & 55 & 76.1 & 79.0 \\
\hline & $8.0 \mathrm{~mL} / \mathrm{L}$ & 480 & 136 & 51 & 45.5 & 87.4 \\
\hline
\end{tabular}

Table 7: Corrosion parameters obtained by impedance measurements for carbon steel in $1.0 \mathrm{M} \mathrm{HCl}$ at various concentrations of Melissa Officinalis oil and extract

\begin{tabular}{lccccc}
\hline Medium & Conc. & $\mathbf{R}_{\mathrm{ct}}\left(\Omega . \mathbf{c m}^{2}\right)$ & $\mathbf{f}_{\text {max }}(\mathbf{H z})$ & $\mathbf{C}_{\mathrm{dl}}\left(\boldsymbol{\mu F} . \mathbf{c m}^{-2}\right)$ & $\mathbf{h}_{\mathbf{z}}(\%)$ \\
\hline Blank & $1.0 \mathrm{M}$ & 29.0 & 100 & 54.9 & - \\
& $0.5 \mathrm{~mL} / \mathrm{L}$ & 97.3 & 40 & 40.9 & 70.1 \\
\multirow{2}{*}{$\mathrm{EO}$} & $1.0 \mathrm{~mL} / \mathrm{L}$ & 169.8 & 40 & 23.4 & 82.9 \\
& $2.0 \mathrm{~mL} / \mathrm{L}$ & 482.9 & 18 & 19.4 & 93.8 \\
& $2.0 \mathrm{~mL} / \mathrm{L}$ & 101.8 & 30 & 52.1 & 71.5 \\
$\mathrm{E}$ & $4.0 \mathrm{~mL} / \mathrm{L}$ & 138.4 & 25 & 46.0 & 79.0 \\
& $8.0 \mathrm{~mL} / \mathrm{L}$ & 173.2 & 20 & 46.0 & 83.2 \\
\hline
\end{tabular}

\section{CONCLUSIONS}

Oil and extract of Melissa Officinalis can act as a natural source and eco-friendly corrosion inhibitor for carbon steel in $1.0 \mathrm{M} \mathrm{HCl}$ solutions. Inhibition efficiency increases with the increase of the concentration of the essential oil and extract of Melissa Officinalis. Tafel polarization measurements 
show that essential oil and extract of Melissa officinalis act essentially as a mixed type inhibitors. The increase in the charge transfer resistance and decrease in the double layer capacitance values, with the increase in the inhibitor concentration, showed that essential oil and extract formed protective layers on the carbon steel surface, covering areas where $\mathrm{HCl}$ solution degrades and corrodes rapidly. The inhibition efficiencies obtained from EIS, Tafel polarization, and weight loss measurements are in reasonable agreement with each other.

\section{REFERENCES}

1. Sorkhabi, H.A.; Seifzadeh, D.; Hosseini, M.G.; Corros. Sci. 2008, 50, 3363-3370.

2. Yýldýz, R.; Doner, A.; Dogan, T.; Dehri, I.; Corros. Sci. 2014, 82,125-132.

3. Prajila, M.; Sam, J.; Bincy, J.; Abraham, J.; J. Mater. Environ. Sci, 2012, 3(6), 1045-1064.

4. Naik, U.J.; Panchal, V.A.; Patel, A.S.; Shah, N.K.; J. Mater. Environ. Sci. 2012, 3, 935946.

5. Al Hamzi, A.; Zarrok, A.H.; Zarrouk, H.; Salghi, A.; Hammouti, R.; Al-Deyab, B.; Bouachrine, S.S.; Amine, M.; Guenoun, A.; Int. J. Electrochem. Sci. 2013, 8, 2586-2605.

6. Zarrouk; A., Hammouti, B.; Zarrok, M.; Warad, H., I.; Bouachrine, M.; Der Pharm. Chem. 2011, 3, 263-271.

7. Hammouti, B.; Salghi, D.; Zarrouk, R.; Messali, A.; Zarrok, M.; Errami, H.; Hammouti, M.; Bazzi, B.; Chakir, L.; Der Pharm. Chem. 2012, 4,1496-1505.

8. Ghazoui, A.; Benchat, N.; Al-Deyab, S.S.; Zarrouk, A.; Hammouti, B.; Ramdani, M.; Guenbour, M.; Int. J. Electrochem. Sci. 2013, 8, 2272-2292.

9. Zarrouk, A.; Zarrok, H.; Salghi, R.; Bouroumane, N.; Hammouti, B.; Al-Deyab, S.S.; Touzani, R.; Int. J. Electrochem. Sci. 2012, 7, 10215-10232.

10. Bendaha, H.; Zarrouk, A.; Aouniti, A.; Hammouti, B.; El Kadiri, S.; Salghi, R.; Touzani, R.; Phys. Chem. News 2012, 64, 95-103.

11. Zarrouk, A.; Hammouti, B.; Zarrok, H.; Bouachrine, M.; Khaled, K.F.; Int. J. Electrochem. Sci. 2012, 7, 89-105.

12. Rekkab, S.; Zarrok, H.; Salghi, R.; Zarrouk, A.; Bazzi, L.; Hammouti, B.; Kabouche, Z.; Touzani, R.; Zougagh, M.; J. Mater. Environ. Sci. 2012, 3, 613-627.

13. Lebrini, M.; Robert, F.; Lecante, A.; Roos, C.;
Corros. Sci. 2011, 53, 687-695.

14. Bouyanzer, A.; Hammouti, B.; Bull. Electrochem. 2004, 20(2), 63-65.

15. Chetouani, A.; Hammouti, B.; Bull. Electrochem. 2003, 19(1), 23-25.

16. Chetouani, A.; Hammouti, B.; Bull. Electrochem. 2004, 20(8), 343-345.

17. Chetouani A.; Hammouti B.; Benkaddour, M.; Pigm. Resin Technol. 2004, 33, 26-31.

18. Benabdellah, M.; Bendahou, M.; Hammouti, B.; Benkaddour, M.; Appl. Surf. Sci. 2005, 252, 6212-6217.

19. El ouadi, Y.; Bouyanzer, A.; Majidi, L.; Paolini, J.; Desjobert, J.M.; Costa, J.; Chetouani, A.; Hammouti, B.; J. Chem. Pharm. Res. 2014, 6(7), 1401-1406.

20. Fouda, A.S.; Abd El Mgeed, A., Abd El-Salam, Sh.; Der Pharma Chemica. 2015, 7(7), 2738.

21. Bouyanzer, A.; Hammouti, B.; Majidi, L.; Mater. Lett. 2006, 60(23), 2840-2843.

22. Bouyanzer, A.; Majidi, L.; Hammouti, B.; Bull. Electrochem. 2006, 22(7), 321-324.

23. ASTM, G 31-72; American Society for Testing and Materials; Philadelphia, PA, 1990.

24. Li, X.H.; Deng, S.D.; Fu, H.; Mu, G.N.; Zhao, N.; Appl. Surf. Sci. 2008, 254, 5574-5586.

25. Satapathy, A.K.; Gunasekaran, G.; Sahoo, S.C.; Amit, K.; Rodrigues, P.V.; Corros. Sci. 2009, 51(12), 2848-2856.

26. Oguzie, E.E.; Corros. Sci. 2008, 50(11), 29932998.

27. El-Etre, A.Y.; Mater. Chem. Phys. 2008, 108(2-3), 278-282.

28. Umoren, S.A.; Obot, I.B.; Obi-Egbedi, N.O.; J. Mater. Sci. 2009, 44(1), 274-279.

29. Szauer, T.; Brandt, A.; Electrochim Acta 1981, 26, 1219-1224.

30. Raicheff, R.; Valcheva, K.; Lazarova, E.; Proceeding of the Seventh European 
Symposium on Corrosion Inhibitors, Ferrara, Italy 1990, 48.

31. Migahed, M.A.; Mohamed, H.M.; Al-Sabagh, A.M.; Mater. Chem. Phys., 2003,80., 169175.

32. Martinez, S.; Stern, I.; Appl. Surf. Sci. 2002, 199(1-4), 83-89.

33. Dahmani, M.; Et-Touhami, A.; Al-Deyab, S.S.; Hammouti, B.; Bouyanzer, A.; Int. J. Electrochem. Sci. 2010, 5, 1060-1070.

34. Ferreira, E.S.; Giancomelli, C.; Giacomelli, F.C.; Spinelli, A.; Mater. Chem. Phys. 2004, 83(1), 129-134.

35. Ashassi-Sorkhabi, H.; Majidi, M.R.; Seyyedi, K.; Appl. Surf. Sci. 2004, 225(1), 176-185.

36. Cao, C., Corros. Sci. 1996, 38, 2073-2082

37. Ostovari, A.; Hoseinieh, S.M.; Peikari, M.; Shadizadeh, S.R.; Hashemi, S.J.; Corros. Sci. 2009, 51(9), 1935-1949.

38. Raja, P.B.; Sethuraman, M.G.; Mater. Lett. 2008, 62(17-18), 2977-2979.

39. Abdel-Gaber, A.M.; Abd-El-Nabey, B.A.; Saadawy, M.; Corros. Sci. 2009, 51(5), 10381042.

40. de Souza, F.S.; Spinelli, A.; Corros. Sci. 2009, 51(3), 642-649.
41. Martinez, S.; Metiko-Hukoviç, M.; J. Appl Electrochem. Soc. 2003, 33(12), 11371142.

42. McCafferty, E.; Hackerman, N.; J. Electrochem. Soc. 1972, 119(2), 146-154.

43. Li, X.; Deng, S.; Fu, H.; Mu, G.; Corros. Sci. 2009, 51(3), 620-634.

44. Sahin, M.; Bilgic, S.; Yýlmaz, H.; Appl. Surf. Sci. 2002, 195, 1-7.

45. Bockris, J.O.; Swinkels, D.A.J.; J. Electrochem. Soc. 1964, 111, 736-743.

46. Herrag, L., El Bali, B., Lachkar, M., Hammouti, B., Oriental Journal of Chemistry, 2009, 25, 265-272.

47. Manssouri, M., El Ouadi, Y., Znini, M., Costa, J., Bouyanzer, A., Desjobert, J-M., Majidi, L., J. Mater. Environ. Sci. 2015, 6, 631-646.

48. Khadraoui, A., Khelifa, A., Hachama, K., Boutoumi, H., Hammouti, B., Chemical Engineering Communications, 2016, 203, 270-277

49. Alaoui Ismaili, K., El Arouji, S., Abdellaoui, A., El Kamani, F., Rais, Z., Filali Baba, M., Taleb, M., Emran, K. M., Zarrouk, A., Aouniti, A., Hammouti, B., Der Pharma Chemica, 2015, $7 N^{\circ} 10,34-44$. 